\title{
Systemic and Neuropathologic Effects of $E$. coli Endotoxin in Neonatal Dogs
}

\author{
RICHARD S. K. YOUNG ${ }^{(33)}$ SUSAN K. YAGEL, AND JAVAD TOWFIGHI \\ Division of Neurology, [R.S.K.Y., S.K.Y.] Department of Pediatrics and Division of Anatomic Pathology, Department \\ of Pathology [J.T.] The Milton S. Hershey Medical Center The Pennsylvania State University, \\ Hershey, Pennsylvania, USA
}

\begin{abstract}
Summary
The acute systemic and neuropathologic effects of $E$. coli endotoxin were determined in neonatal dogs. Administration of sublethal $\left(L D_{0}\right)$, moderate $\left(L D_{50}\right)$, or lethal $\left(L D_{100}\right)$ doses of endotoxin produced significant arterial hypotension, metabolic (lactic) acidosis, and hypoglycemia. Neuropathologic changes consisted of widespread inflammation in both grey and white matter; however, necrotic lesions were found only in forebrain white matter.
\end{abstract}

Bacterial infections in the human infant are an important cause of subsequent mental retardation, cerebral palsy, and epilepsy (18, $22,23,25)$. The morbidity and mortality associated with perinatal bacterial infections have been attributed to bacterial endotoxin, a lipopolysaccharide component of the bacterial cell wall. Because administration of endotoxin to laboratory animals mimics human septicemia $(1,4,8,14)$, the systemic and neuropathologic disturbances induced by endotoxin are of considerable interest.

Studies by Gilles et al. (12) have shown that administration of $E$. coli endotoxin to newborn kittens produces extensive brain injury. The acute systemic changes occurring during neonatal endotoxemia have not been described in detail. We, therefore, undertook a series of experiments in neonatal dogs to determine the acute neuropathologic changes occurring during endotoxemia as well as the critical physiologic and and metabolic parameters (blood pressure, heart rate, arterial blood gases, glucose, and lactate levels), which might be associated with those neuropathologic changes. Although these systemic parameters have not been studied during endotoxemia in the neonatal dog, they have been shown to be important predictors of mortality in the endotoxintreated adult $\operatorname{dog}(5,9,17,20)$.

\section{MATERIALS AND METHODS}

Dose-response curve. Mongrel dogs, 1-10 days of age, were selected because their state of neurologic development at birth resembles that of the human infant of approximately $34-40 \mathrm{wk}$ gestation (16). Trials were conducted in 16 animals to determine the dose of $E$. coli endotoxin that would result in 0,50 , and $100 \%$ mortality when injected subcutaneously. A lyophilized preparation of endotoxin from $E$. coli 055:B5 (Difco Laboratories) was chosen because this organism is a pathogen for human neonates, may be transmitted by nursery personnel (28), and has been previously used in neuropathologic experiments (12).

Systemic responses to graded endotoxemia. The physiologic and metabolic responses of the animals were examined before and after administration of endotoxin. The animals were rapidly anesthetized with halothane $(0.5-3.5 \%)$ in oxygen by mask. After infiltration of a local anesthetic (xylocaine, 1\%), the femoral artery was exposed and catheterized with a 30 gauge Teflon catheter to monitor arterial blood pressure (Beckman, R711). Intermittent $200 \mu$-samples of arterial blood were withdrawn for determination of arterial blood gases (Radiometer, model BMS 3-MK 2). Addi- tional $20-\mu$ l samples of arterial blood were obtained hourly for determination of plasma glucose and lactate levels by fluorometric analysis according to the method of Lowry and Passoneau (19). Body temperature was monitored by means of a rectal thermocouple (Yellow Springs) and maintained by a servo-controlled heating lamp. After insertion of the catheter, halothane was withdrawn and the animals allowed to spontaneously breathe room air. The wound was sutured and periodically infiltrated with xylocaine, $1 \%$. A low $\left(\mathrm{LD}_{0}\right)$, moderate $\left(\mathrm{LD}_{50}\right)$, or high $\left(\mathrm{LD}_{100}\right)$ dose of $E$. coli endotoxin was then injected subcutaneously, and the animals monitored for $4 \mathrm{~h}$. Control animals $(n=5)$ were similarly catheterized and monitored but instead received an intraperitoneal injection of sterile saline.

Acute neuropathologic effects of graded endotoxemia. After the 4-h period of monitoring, the animals were gavage-fed powdered bitch's milk (Esbilac, Borden) and placed in a thermostatically controlled incubator at $32^{\circ} \mathrm{C}$. Twenty-four hours later they were anesthetized with an intraperitoneal injection of pentobarbital sodium. A thoracotomy was performed and the animals were perfuse-fixed with FAM (formalin-acetic acid-methanol in a ratio of $1: 1: 8$ ), which was injected through the aorta. The brains were removed, processed, and embedded in paraffin. Ten-micron sections were cut and stained with hematoxylin and eosin, cresyl violet, luxol fast blue, and phosphotungstinic acid-hematoxylin.

\section{RESULTS}

Dose-response trials. Animals receiving $6 \mathrm{mg} / \mathrm{kg}$ of endotoxin $(n=4)$ quickly became lethargic and listless. All died within 12 $\mathrm{h}$ after endotoxin administration $\left(\mathrm{LD}_{100}=\right.$ high dose). Dogs given smaller doses of endotoxin developed coryza and became inactive but mortality was less. Half of the animals receiving $2-4 \mathrm{mg} / \mathrm{kg}$ $(n=6)$ of endotoxin $\left(\mathrm{LD}_{50}=\right.$ moderate dose) died. There were no deaths in the group $(n=3)$ receiving $0.5-1.0 \mathrm{mg} / \mathrm{kg}\left(\mathrm{LD}_{0}=\right.$ low dose) of endotoxin.

Systemic effects of graded endotoxemia. Marked metabolic derangements also followed the injection of endotoxin. A significant $(P<0.05$, Student's $t$ test) dose-related decline in $\mathrm{pH}$ occurred at every hour after endotoxin administration in the experimental animals (Fig. 1). At $3 \mathrm{~h}$, the $\mathrm{pH}$ of the control animals was 7.42 \pm 0.03 (all values are mean \pm s.e.). The $\mathrm{pH}$ of the animals administered a low dose of endotoxin was $7.27 \pm 0.02(P<0.001)$; of those given a moderate dose, $7.24 \pm 0.02(P<0.001)$; and of those receiving a high dose, $7.18 \pm 0.02(P<0.001)$. There were no significant changes in arterial $\mathrm{PO}_{2}$ or $\mathrm{PCO}_{2}$ levels.

Alterations in plasma glucose and lactate levels (Fig. 2 and 3) also developed in the endotoxin-treated animals. Arterial glucose levels in the control animals declined slightly during the 4-h period of observation. In contrast, the experimental animals developed an initial mild (nonsignificant) increase in arterial glucose levels, followed by a profound fall in glucose concentrations. Four hours after endotoxin administration, the glucose concentration of the low dose group was $1.94 \pm 0.6$ mole/liter $(P<0.01)$ and 


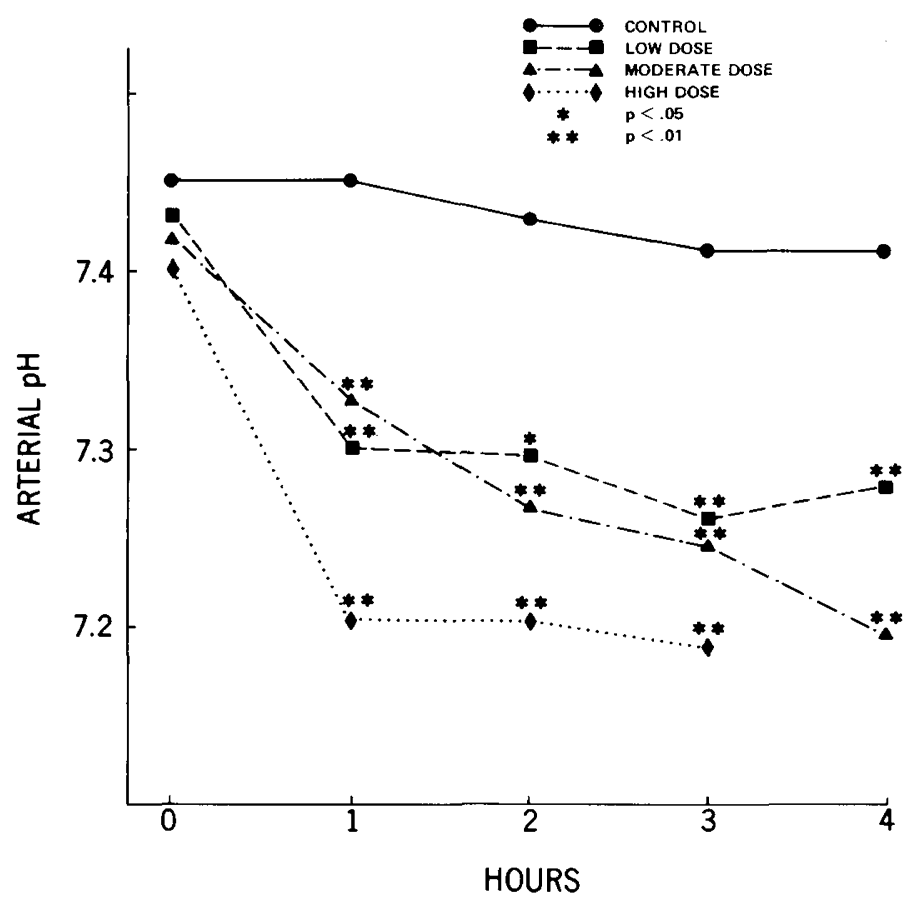

Fig. 1. Arterial $\mathrm{pH}$ in control and endotoxin-treated animals.

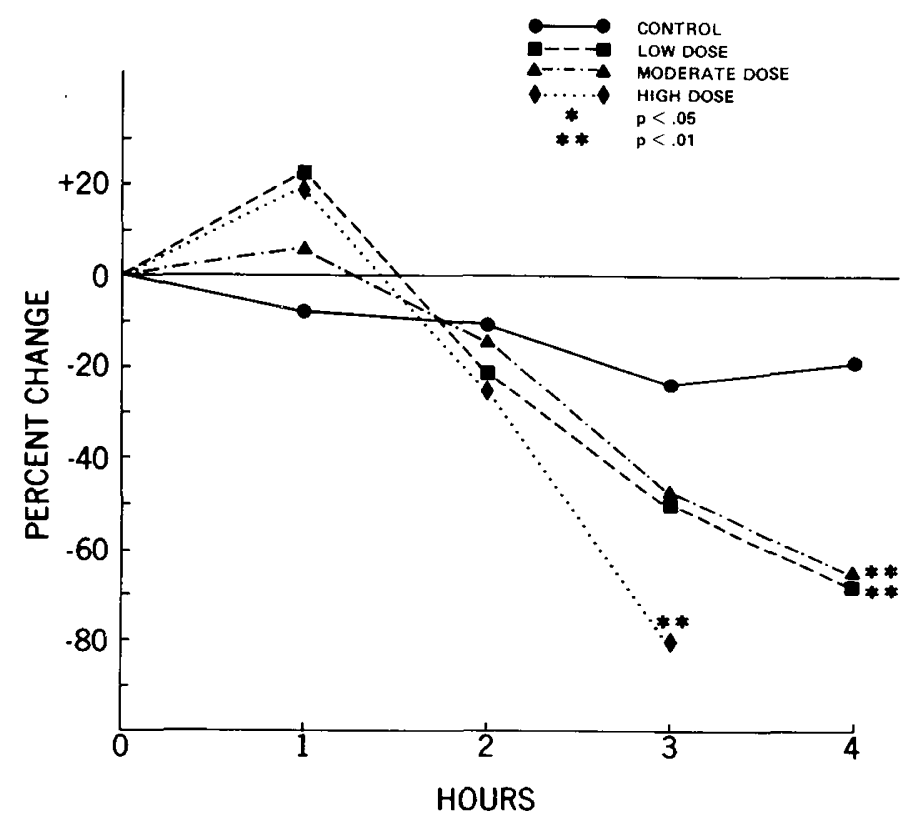

Fig. 2. Percent change in arterial glucose levels in control and endotoxin-treated animals.

that of the moderate dose group, $2.19 \pm 0.16 \mathrm{mmole} /$ liter $(P<$ 0.001 ), was in contrast to that of the control animals, $4.7 \pm 0.5$ mmole/liter (Fig. 2). At $3 \mathrm{~h}$, arterial lactate concentrations in the control animals was $2.09 \pm 0.24 \mathrm{mmole} / \mathrm{liter}$, compared to 4.17 $\pm 1.16(P<0.05)$ in the low dose group, $2.81 \pm 0.16(P<0.05)$ in the moderate dose group, and $3.83 \pm 0.8 \mathrm{mmole} /$ liter $(P<0.05)$ in the high dose group (Fig. 3).

Mean arterial blood pressure declined significantly in all experimental groups compared to control animals (Fig. 4). Three hours after endotoxin administration, mean arterial blood pressure of the control group was $67 \pm 5 \mathrm{mmHg}$ in contrast to the low dose group ( $39 \pm 3 \mathrm{mmHg}, P<0.01$ ), to the moderate dose group (44 $\pm 4 \mathrm{mmHg}, P<0.01)$, and to the high dose group $(41 \pm 2 \mathrm{mmHg}$, $P<0.01)$. The heart rate and temperature of the experimental groups did not differ significantly from those of the control.
Acute neuropathologic effects of graded endotoxemia. The brains of animals, which had been given $6 \mathrm{mg} / \mathrm{kg}$ of endotoxin and had died of hypotension within 3-12 h of injection, appeared normal on gross and microscopic inspection. Dogs, which had been given smaller doses of endotoxin and had survived, were afebrile and appeared clinically well at $24 \mathrm{~h}$; however, their brains showed widespread inflammation, which was characterized by intense polymorphonuclear inflammatory infiltrate that equally affected cortical and deep gray matter, white matter (Fig. 5 and 6), brainstem (Fig. 7), and cerebellum. The infiltrate was most marked in the perivascular regions, but polymorphonuclear leukocytes were also evident deep within the neuropil.

Extensive areas of coagulative necrosis were present with prominent axonal spheroids in the cerebral white matter (Fig. 6). Necrosis was particularly prominent in the white matter of corpus callosum, anterior commissure (Fig. 6), and of the periventricular regions (Fig. 5). In rare instances, injury extended into gray matter structures adjacent to the necrotic white matter (Fig. 5). The intensity of pathologic injury was more severe in animals which

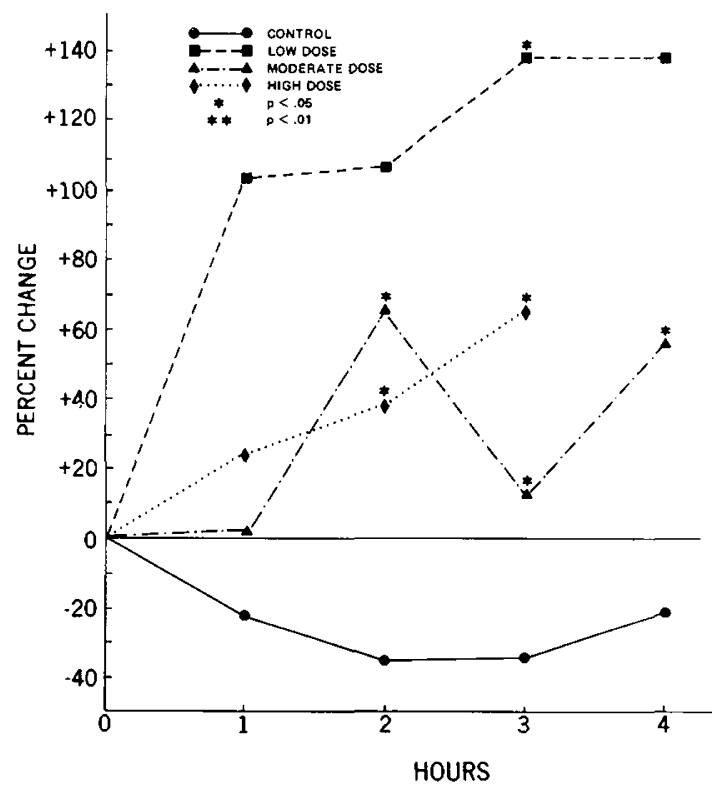

Fig. 3. Percent change in arterial lactate levels in control and endotoxin-treated animals.

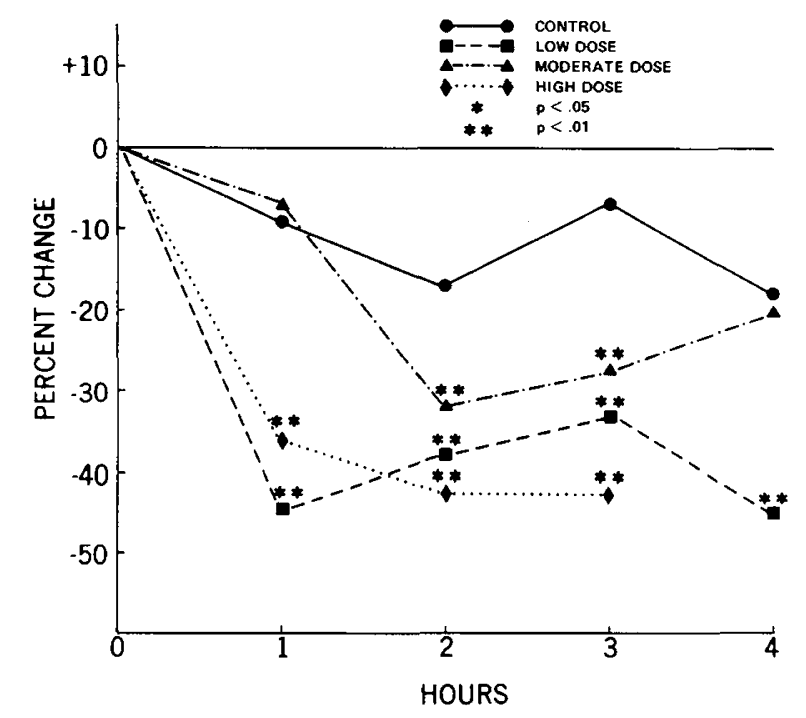

Fig. 4. Percent change in arterial blood pressure in control and endotoxin-treated animals. 


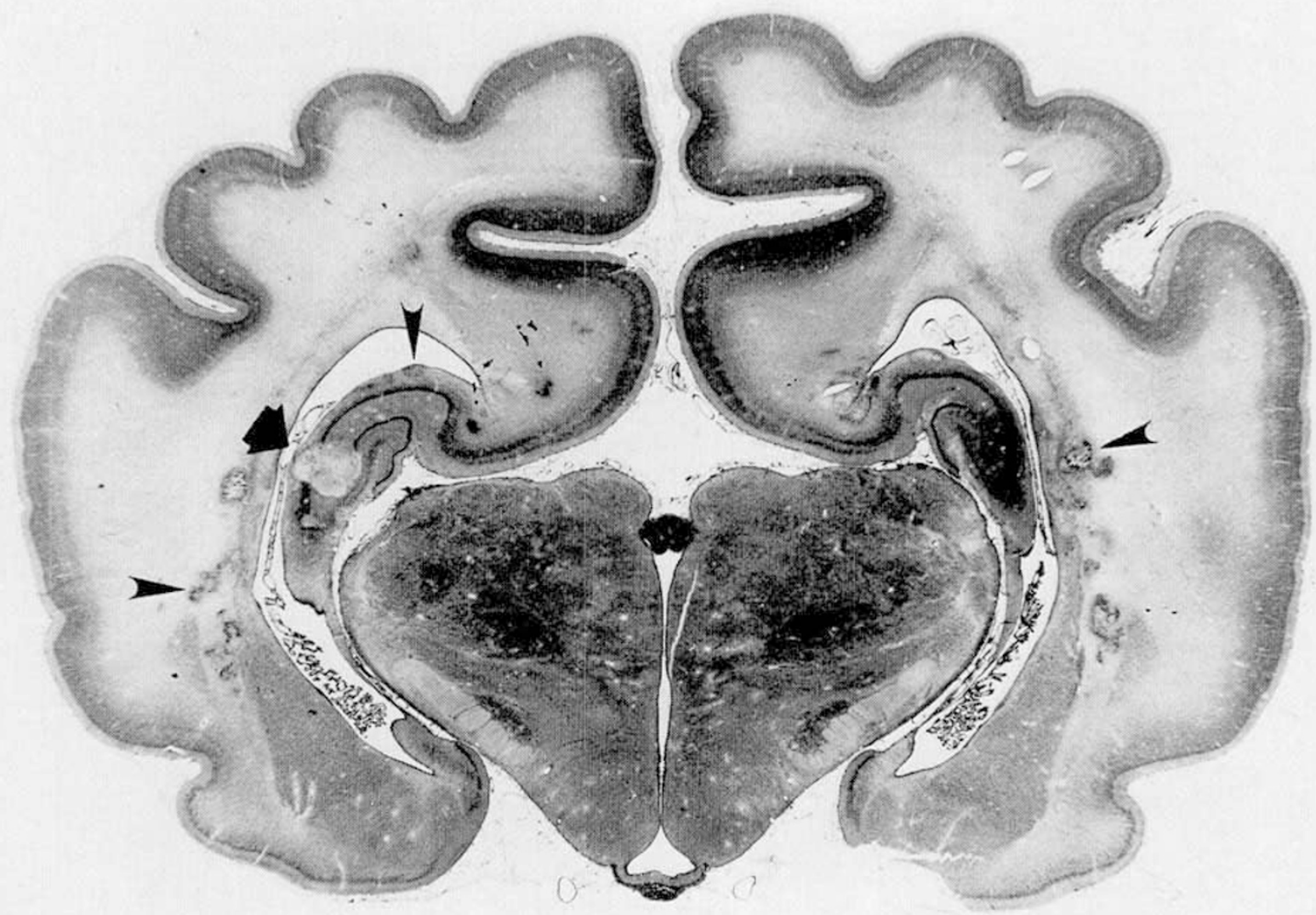

Fig. 5. Coronal section of brain. There are numerous foci of necrosis in the periventricular white matter (arrowheads). One lesion has extended to secondarily involve the hippocampus (arrow). Luxol fast blue, $\times 5.5$.

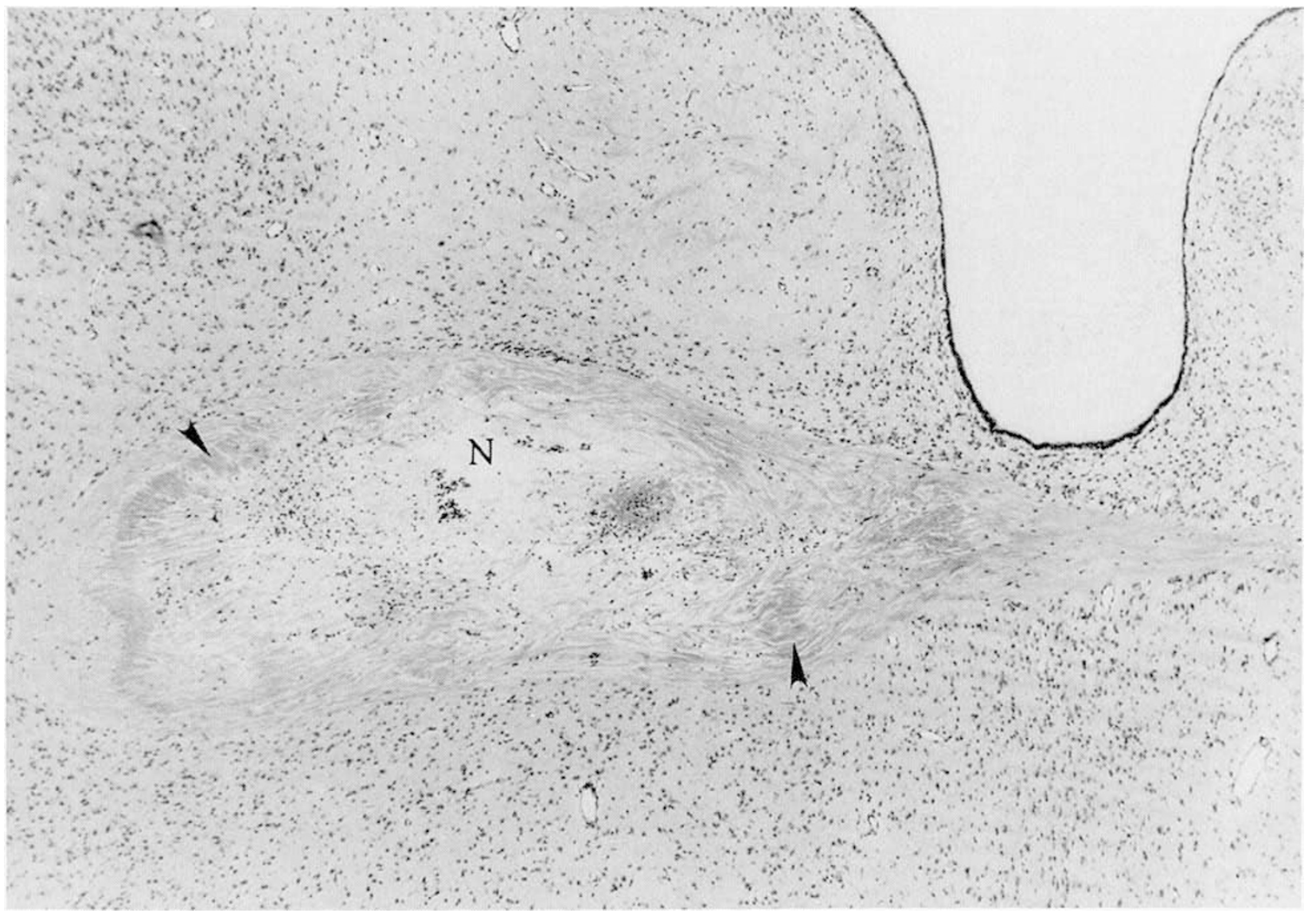

Fig. 6. Anterior commissure. There are many polymorphonuclear leukocytes within an area of necrosis $(N)$ in the anterior commissure. Axonal spheroids (arrowheads) are conspicuous in the periphery of the lesion. Hematoxylin and Eosin, $\times 90$. 


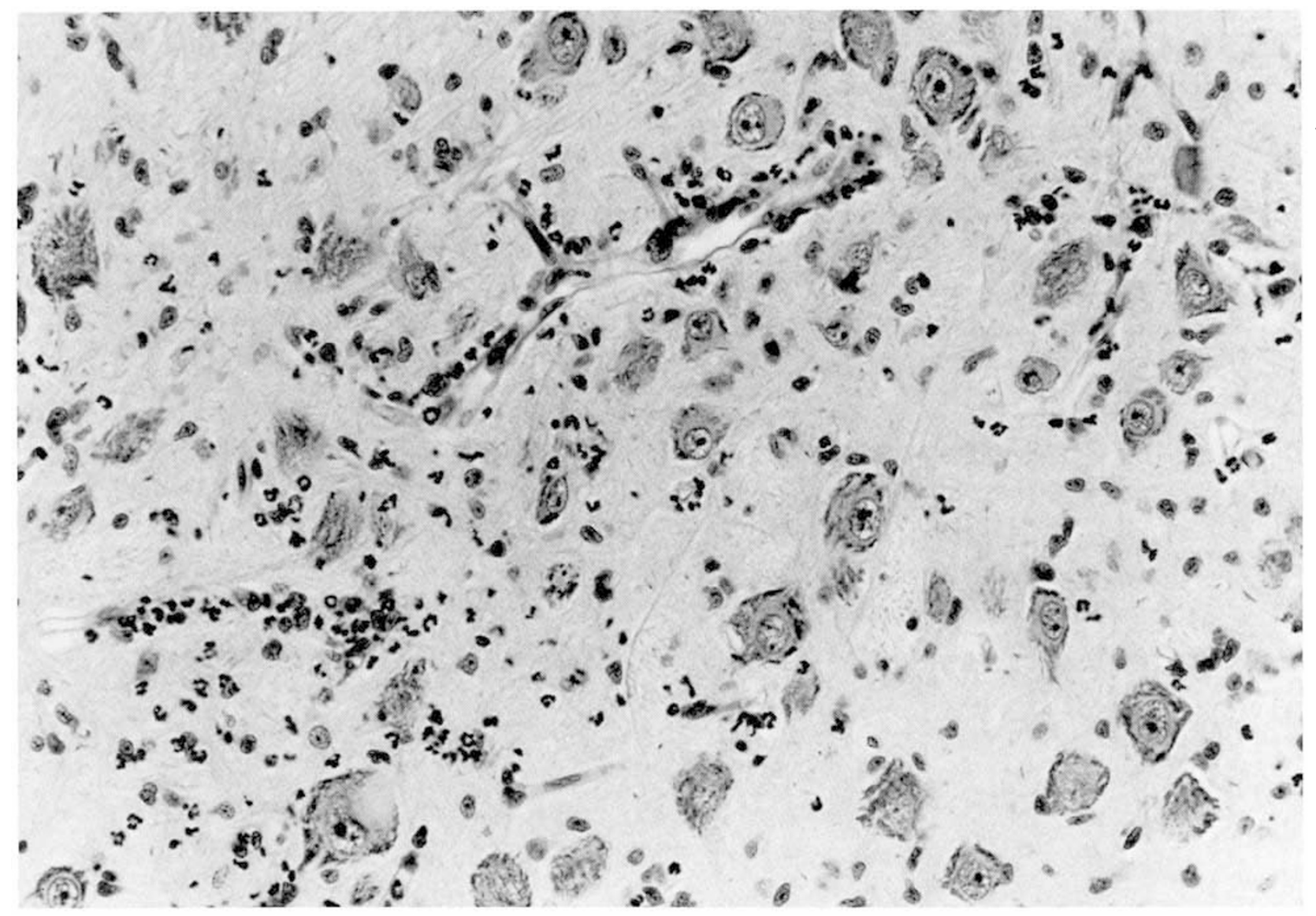

Fig. 7. Pontine tegmentum. Numerous polymorphonuclear leukocytes are present both in the perivascular spaces and parenchyma of the pontine tegmentum. Hematoxylin and Eosin, $\times 560$.

received $4 \mathrm{mg} / \mathrm{kg}$ of endotoxin and minimal in those given only $0.5 \mathrm{mg} / \mathrm{kg}$.

Histologic sections from the liver, lung, kidney, spleen, and heart were also examined. None of these organs showed areas of necrosis such as was present in brain, although the spleen did contain polymorphonuclear infiltrates.

\section{DISCUSSION}

The metabolic alterations observed in our endotoxin-treated neonates parallel those reported in their adult counterparts. Just as adult dogs develop a metabolic acidosis soon after endotoxin exposure $(5,20)$, neonatal dogs also develop a metabolic acidosis when exposed to even low doses of endotoxin. Slightly less than one-half of the total base deficit in the endotoxin-treated animals can be attributed to accumulation of lactate (moderate dose group at $4 \mathrm{~h}$ : base deficit, $10 \mathrm{mmole} /$ liter and lactate, $4.5 \mathrm{mmole} /$ liter). The increase in lactate presumably results from impaired tissue perfusion (14). A combination of other organic acids and ketoacids account for the remainder of the metabolic acidosis $(5,20$, 26, 27).

Administration of small doses of endotoxin to neonatal dogs causes an initial hyperglycemia followed by profound hypoglycemia, much as occurs in the adult dog. The initial hyperglycemia is related to glycogenolysis and gluconeogenesis, whereas the profound hypoglycemia is due to depletion of hepatic glycogen and increased glucose oxidation (9). Endotoxin-induced hypoglycemia may be fatal in some species (7). Conversely, maintenance of arterial glucose may prevent death in adult dogs during otherwise irreversible endotoxin shock (17).

The significant arterial hypotension (without corresponding changes in heart rate), which occurred in these neonatal animals, is similar to that which develops in the endotoxin-treated adult $\operatorname{dog}(5,20)$. Endotoxin-induced hypotension is believed to be related to the release of vasoactive substances (histamine, serotonin, and kinins) with secondary peripheral pooling of blood and to a direct myocardial depressant effect of endotoxin.

Few studies of the neuropathologic potential of endotoxin have concentrated on the perinatal period $(1,21)$. The teratologic potential of endotoxin has been evaluated in fetal rats and rabbits $(15,24)$. These studies demonstrate an increased incidence of central nervous system anomalies (hydrocephalus, microcephaly, anopthalmia) after endotoxin exposure; however, the paucity of cerebral white matter in the fetal rat brain renders the animal a poor experimental model to study a disorder that has a predilection for white matter injury (12).

The sole investigation of the neuropathologic potential of endotoxin in the neonatal animal was conducted by Gilles et al. (12). Small doses of $E$. coli endotoxin administered to neonatal kittens resulted in astrogliosis, calcifications, and necrotic cystic lesions in forebrain white matter in over $90 \%$ of the animals. These investigations also disclosed acute inflammation, but principal attention was directed toward elucidating the chronic, rather than the acute histologic reaction. Our neuropathologic findings of multiple necrotic lesions in cerebral white matter are most likely the forerunner of the chronic cystic cavities noted in endotoxin-treated animals (12).

These studies document the intense inflammatory response induced by endotoxin in the brain of the neonatal dog. Previous studies have established that endotoxin has a propensity for causing inflammation and vascular damage. A widespread inflammatory response consisting of sweiling of endothelial cells, migration of neutrophils, edema, and extravasation of cellular elements has been reported in organs other than the brain (13). Light and ultrastructural techniques have documented the ability of endotoxin to damage the vascular endothelium $(3,6,11)$. Inflammatory 
changes have also been noted in the brains of humans dying of septic shock (11).

Can the brain lesions in our animals be ascribed solely to the inflammatory effect of endotoxin alone? What role is played by the concomitant hypotension, acidosis, and hypoglycemia? The multiple derangements associated with endotoxemia make these questions difficult to answer with any certainty (7). Because endotoxin elicits an inflammatory response throughout the central nervous system, the confinement of necrotic lesions to the white matter of the forebrain remains puzzling. Nonetheless, it is unlikely that inflammation, which was present in both cerebral grey and white matter and brainstem, would result in necrosis only of cerebral white matter. In addition, acidosis and hypoglycemia in the absence of hypoxia are not known to produce cerebral white matter damage $(2,10)$. It is conceivable that regional disturbances in brain blood flow or metabolism in telencephalic white matter may render these areas selectively vulnerable. Preliminary studies suggest that significant hypotension may result in selective ischemia of forebrain white matter (29). Further studies to define the cerebrovascular and cerebral metabolic changes occurring during neonatal endotoxemia are in progress.

\section{REFERENCES AND NOTES}

1. Bech-Jansen, P., Brinkman, C. R., Johnson, G. H., and Assali, N. S.: Circulatory shock in pregnant sheep: effects of endotoxin on uteroplacental and fetal umbilical circulation. Am. J. Obstet. Gynecol., 112: 1084 (1972)

2. Brierly, J. B.: Cerebral hypoxia. In: W. Blackwood and J. A. N. Corsellis, Eds., Greenfields Neuropathology, p. 76 (Year Book, Chicago, 1976)

3. Clawson, C. C., Hartmann, J. F., and Vernier, R. L.: Electron microscopy of the effect of gram negative endotoxin on the blood brain barrier. J. Comp. Neurol., I27: $183(1966)$

4. Corrigan, J. J.: Heparin therapy in bacterial septicemia. J. Pediatr., 91: 695 (1977).

5. Dobbins, D. E., Marciniak, D. L., Gersabeck, E. F., Maciejko, J. J., and Grega, G. J.: Evidence for a centrally mediated hypotensive effect of escherichia coli endotoxin in the anesthetized dog. J. Pharmacol. Exper. Therap., 203: 47 (1977).

6. Drommer, W.: Feinstruktur der normalen arteriolen and ihre alterationen nach experimentallem colitoxinschock in zentralen nerven system des schweines. Acta/Neuropath. (Berlin), 22: 29 (1972).

7. Elin, R. J. and Wolff, S. M.: Biology of endotoxin. Ann. Rev. Med., 27: 127 (1976).

8. Fenton, L. J. and Strunk, R. C.: Complement activation and group b streptococcal infection in the newborn: similarities to endotoxin shock. Pediatrics, 60: 901 (1977).

9. Filkins, J. P.: Phases of glucose dyshomeostasis in endotoxicosis. Circ. Shock, 5: 347 (1978).

10. Friede, R. L., Developmental Neuropathology. New York, Springer, 1975, pp. 44-51.

11. Graham, D. I., Behan, P. O., and More, I. A. R.: Brain damage complicating septic shock. J. Neurol. Neurosurg. Psych. 42: 19 (1979).

12. Gilles, F. H., Averill, D., and Kerr, C. S.: Neonatal endotoxin encephalopathy. Ann. Neurol., 2: 49 (1977).
13. Goodman, M. L., Way, B. A., and Irwin, J. W.: The inflammatory response to endotoxin. J. Pathol., 128: 7 (1979).

14. Guenter, C. A., Fiorcia, V., and Hinshaw, L. B.: Cardiorespiratory and metabolic responses to live E. coli and endotoxin in the monkey. J. Appl. Physiol., 26 780 (1969).

15. Hellmann, W.: Endotoxin, fever and anomalies of development in rabbits. Arzneim-Forsch/Drug Res., 29: 1062 (1979).

16. Himwich, W. A.: Problems in interpreting neurochemical changes occurring in developing and aging animals. Progr. Brain. Res., 40: 13 (1973).

17. Hinshaw, L. B., Peyton, M. D., Archer, L. T., Black, M. R. Coalson, J. J., and Greenfield, L. J.: Prevention of death in endotoxic shock by glucose administration. Surg. Gynecol. Obstet., 139: 851 (1974).

18. Leviton, A., Gilles, F. H., and Dooling, E. C.: The epidemiology of perinata telencephalic leukoencephalopathy characterized by hypertrophic astrocytes and amphophilic globules. Neurology. 29: 571 (1979).

19. Lowry, O. H. and Passonneau, J. V.: A flexible system of enzymatic analysis New York, Academic Press, 1972.

20. Miller, T. H., Priano, L. L., Jorgensen, J. H., and Traber, D. L.: Cardiorespiratory effects of pseudomonas and E. coli endotoxins in the awake dog. Am. J. Physiol. 232(6): H682 (1977).

21. Morishima, H. O., Niemann, W. H., and James, L. S.: Effects of endotoxin on the pregnant baboon and fetus. Am. J. Obstet. Gynecol., 131: 899 (1978).

22. Naeye, R. L.: Causes of the excessive rates of perinatal mortality and prematurity in pregnancies complicated by maternal urinary tract infections. N. Engl. $\mathbf{J}$. Med., 300: 819 (1979)

23. Niswander, K. R. and Gordon, M.: The Women and Their Pregnancies. The Collaborative Perinatal Study of the National Institute of Neurological Diseases and Stroke. pp. 252-256 (Saunders, Philadelphia, 1972).

24. Ornoy, A. and Altshuler, G.: Maternal endotoxemia, fetal anomalies and central nervous system damage. Am. J. Obstet. Gynecol. 124: 196 (1976).

25. Patrick, M. J.: Influence of maternal renal infection on the foetus and infant Arch. Dis. Child., 42: 203 (1967)

26. Rosenberg, J. C. and Rush. B. F.: Lethal endotoxic shock: oxygen deficit, lactic acid levels, and other metabolic changes. J. Am. Med. Assoc., 196: 87 (1966).

27. Siegel, J. H., Cerra, F. B., Border, J. R., Coleman, B., and McMenamy, R. Human response to sepsis. In: Cowley, R. A., Trump, B. F., eds., Pathophysiology of Shock, Anoxia, and Ischemia. p. 251. (Williams and Wilkins, Baltimore, 1982)

28. Wright, J. and Roden, A. T.: Escherichia coli 055:B5 infection in a gastroenteritis ward. Am. J. Hyg., 58: 133 (1953).

29. Young, R. S. K., Hernandez, M. J., and Yagel, S. K.: Selective reduction of blood flow to white matter during hypotension in newborn dogs. Ann. Neuro. 12 . 445 (1982).

30. We are grateful to Drs. Floyd Gilles and E. P. Richardson, Jr., for reviewing the neuropathologic material; to Dr. Jeanne B. Li for critical review of the manuscript; to Tina Gingrich and Mae Wallace for secretarial assistance, and to Dr. Nicholas M. Nelson for his wholehearted encouragement.

31. This work was done during the tenure of a Clinician-Scientist Award (Dr. Young) from the American Heart Association and with funds contributed in part by its Pennsylvania Affiliate, and was supported by research grants from the Pennsylvania State University and grant R23 NS 18039 (Dr. Young) from the National Institute of Neurologic, Communicative Disorders, and Stroke, N.I.H.

32. Presented in part at the Annual Conference of the American Academy of Neurology, Toronto, May 2, 1982.

33. Requests for reprints should be addressed to: Dr. Richard S. K. Young, Division of Neurology, Department of Pediatrics, The Milton S. Hershey Medical Center, The Pennsylvania State University, Hershey, Pennsylvania 17033.

34. Received for publication July 1, 1982

35. Accepted for publication December 2, 1982 